\title{
Association between myopia and central corneal thickness among patients in a tertiary hospital in south-south Nigeria
}

\begin{abstract}
Background: Myopia also called near or short sightedness is a refractive defect of the eye in which collimated light produces image focus in front of the retina. The aetiology is uncertain but several parameters have been studied with conflicting results. This study aims to determine if there is an association between central corneal thickness and myopia among patients attending a tertiary. Eye Center in South-South Nigeria.
\end{abstract}

Methodology: The study subjects and controls were sampled from patients attending the Eye Clinic of University of Port Harcourt Teaching Hospital, who had no previous history of ocular trauma, intraocular surgeries or contact lens wear. Their visual acuities (VA) were assessed with a Snellen chart and those with VA of 6/6 or better; and those who had improvement with pinhole were selected. They were further examined using the Keeler direct ophthalmoscope, 78D lens, and slit lamp biomicroscope. Those with cataract, glaucoma or posterior segment lesions were excluded from the study. All study subjects were refracted using an auto refractor (Carl Zeiss Meditec) and the refraction subjectively refined with trial lenses. The subjects were categorized into: emmetropia (Plano) and myopes who were subjects with spherical equivalent of between $\leq-0.5 \mathrm{D}$ and $\geq-6.0 \mathrm{D}$. The myopes were further divided into low myopia $(<-3.0 \mathrm{D})$, moderate myopia $(>-3.0 \mathrm{D}$ to $<$ $-6.0 \mathrm{D})$ and high myopia (>-6.0D). The myopes were the study cases while the emmetropes were the controls. The central corneal thickness (CCT) was measured using ultrasound pachymeter (IOPAC, Heidelberg engineering, Germany).

Result: There were 160 study subjects ( 320 eyes) comprise of 80 myopes (160 eyes) and 80 controls (160 eyes). The mean age of the myopes was $23.54 \pm 12.74$ years while that of the controls was $23.62 \pm 12.86$ years. The difference in mean age between the two groups was however not statistically significant $(\mathrm{P}=0.968)$. The age range of the respondents was $10-65$ years. Among the myopes, $42(52.5 \%)$ were males and $38(47.5 \%)$ females giving a male to female ratio of 1.1:1. The control group had $32(40.0 \%)$ males and $48(60 \%)$ females giving a male to female ratio of 2:3.There was a total of 74 males and 86 females giving a ratio of $(\mathrm{M}: \mathrm{F}=1: 1.1)$. This difference in gender representation was however not statistically significant $(\mathrm{p}=0.416)$. The mean central corneal thickness $(\mathrm{CCT})$ for myopes was $530.34 \pm 49.00 \mu \mathrm{m}$ while that of controls was $533.82 \pm 38.03 \mu \mathrm{m}$. The difference was statistically significant $(\mathrm{P}=0.001)$. There was however no correlation between myopia and $\mathrm{CCT}(\mathrm{r}=0.0, \mathrm{r} 2=0.0, \mathrm{CI}=0.45-0.45)$.

Conclusion: This study showed that myopes have lower CCT compared to emmetropes and this difference is statistically significant. There is therefore a need to educate myopic patients and the populace on the need to have glaucoma assessment because of the risk associated with thin corneas. Our study also found no correlation between myopia and CCT.
Volume 5 Issue 2 - 2016

\author{
Chinawa Ndubuisi Elijah,' Pedro Egbe $\mathrm{CN}{ }^{2}$ \\ Ejimadu $\mathrm{CS}^{3}$ \\ 'Mercy hospital Abak/Siloam eye foundation, Nigeria \\ ${ }^{2}$ Department of Ophthalmology, University of Port Harcourt \\ Teaching Hospital, Nigeria \\ ${ }^{3}$ University of Port Harcourt Teaching Hospital, Nigeria
}

Correspondence: Chinawa Ndubuisi Elijah, Mercy hospital Abak/Siloam eye foundation, Nigeria, Tel +234 803 7853668, Email favouredchinawa@gmail.com

Received: October 06, 2016 | Published: October 14, 2016
Abbreviations: VA, visual acuities; CCT, central corneal thickness; AL, axial length; IOP, intraocular pressure; CI, confidence interval

\section{Introduction}

Myopia is one of the most common eye disorders worldwide. It affects about $25 \%$ of the population in the West and over $80 \%$ in some Asian regions. ${ }^{1}$ Changes related to myopic eyes include elongated axial length (AL) and stretching of the retina, choroid and sclera. ${ }^{2}$ Patients with severe forms of myopia or high myopia are more susceptible to other ocular abnormalities such as lacquer cracks, retinal detachment, chorioretinal atrophy, glaucoma, staphyloma, choroidal neovascularization, macular hole, dislocation of lens, amblyopia etc. ${ }^{3}$
Although the true aetiology of myopia is still unknown, ${ }^{4}$ the cornea is responsible for approximately two-thirds of optical refraction and its role in myopia has consequently been studied intensely over the years. It becomes necessary to explore the possible aetiologies or risk factor of myopia among patients in a tertiary center in South-South Nigeria.

Intraocular pressure (IOP) has been hypothesized to be one of several factors implicated in the pathogenesis of myopia. ${ }^{5}$ Elevated IOP is said to impose scleral stress and creep, resulting in axial eye elongation with scleral stretch. ${ }^{6}$ Rather than IOP, ocular rigidity is said to play an important role in the pathogenesis of myopia as human sclera was found to be related to the refractive status since scleral rigidity is weak in myopes. ${ }^{7}$ On the other hand, some other studies reported a poor correlation between the degree of myopia and ocular 
rigidity. ${ }^{8}$ The cornea and sclera together form the outer fibrous tunic of the eye and withstand both internal and external forces to maintain the eyeball shape. Whether a change in the biomechanical properties leads to axial length elongation and anterior chamber deepening, which subsequently results in the decreased scleral/corneal thickness and elasticity, remains controversial. ${ }^{9-11}$ While a study found that myopic subjects had thicker central corneal thickness, ${ }^{12}$ others reported thinner $\mathrm{CCT}^{13,14}$ and yet others found no correlation between CCT and myopia. ${ }^{15}$ We embarked on this study to establish whether there is actually an association between myopia and CCT in our region of Nigeria.

\section{Methodology}

A comparative cross sectional hospital-based study was used in order to measure the characteristics and responses of the sampled population on the specified variables of the study. Patients attending the Eye Clinic of UPTH who had no history of ocular trauma, intraocular surgeries or contact lens wear were recruited for the study. Other inclusion criteria were absence of cataract or glaucoma, normal posterior segment findings, and a visual acuity that improved with pin-hole. Those who had refractive error were consecutively recruited and further sought after refraction. The myopes were used for the study. A structured interviewer-administered questionnaire was used. The questionnaire was administered by the author. It was redesigned after a pretest with a pilot group at the University of Port Harcourt Teaching Hospital using subjects aged between 10 to 50 years. The control and study subjects were sampled from patients attending the Eye Clinic of UPTH, who had no prior history of ocular trauma, intraocular surgeries or contact lens wear. All subjects had visual acuity (VA) assessment using Snellen's chart and those with VA of 6/6 or better; and whose VA improved with pin-hole were recruited into the study. The subjects were further examined using Keeler direct ophthalmoscope, $+78 \mathrm{D}$ lens and slit lamp biomicroscope.

The patients were then refracted using autorefractor (Carl Zeiss Meditec) and refraction subjectively refined with trial lenses. The subjects were categorized into: emmetropia (plano) and myopes who were subjects with spherical equivalent of between $\leq-0.5 \mathrm{D}$ and $\geq-6.0 \mathrm{D}$. The myopes were further divided into low myopia $(<-3.0 \mathrm{D})$, moderate myopia $(>-3.0 \mathrm{D}$ to $<-6.0 \mathrm{D})$ and high myopia $(>-6.0 \mathrm{D})$. The myopes were the cases while the emetropes were the controls. The central corneal thickness were measured using ultrasound pachymeter (10PAC, Heidelberg engineering, Germany). Five readings were taken automatically and the average recorded. Patients were seated in front of the machine with their eyes anaesthetized with topical anaesthesia (tetracaine 1\%) and measurements taken with the probe perpendicular to the eye. Data was collated and analyzed using Epiinfo version $6.04 \mathrm{~d}$ statistical software. Test of significance between proportions was assessed using chi-square $\left(X^{2}\right)$ with a $\mathrm{p}$ value of $<$ 0.05 considered as significant. When some cells had 0 or $<5$, Fishers Exact test was used. Test of significance between means was tested using student-t test with a $p$ value of $<0.05$ considered as significant Correlation analysis with the Pearson test was used to study relations between continuous variables, represented by the letter " $r$ " and a $95 \%$ confidence interval (CI) was also measured. Mantel-Haenszel chisquare test for linear trend was used for the comparison of variables with a trend. Data was presented in percentages as tables and graphs accordingly (Table 1).
Table I Central corneal thickness of myopes and controls

\begin{tabular}{lll}
\hline $\begin{array}{l}\text { Central Corneal } \\
\text { Thickness }(\boldsymbol{\mu m})\end{array}$ & $\begin{array}{l}\text { Myopia (Both Eyes) } \\
\text { Frequency (\%) }\end{array}$ & $\begin{array}{l}\text { Control (Both Eyes) } \\
\text { Frequency (\%) }\end{array}$ \\
\hline$<450$ & $8(5.0)$ & $1(0.6)$ \\
$450-499$ & $40(25.0)$ & $38(23.7)$ \\
$500-550$ & $59(36.9)$ & $62(38.8)$ \\
$551-600$ & $40(25.0)$ & $51(32.0)$ \\
$>600$ & $13(8.1)$ & $8(5)$ \\
Total & $160(100.0)$ & $160(100.0)$ \\
\hline
\end{tabular}

\section{Result}

There did 160 study subjects ( 320 eyes) comprise 80 myopes (160 eyes) and 80 control (160 eyes). The mean age of the myopes was $23.54 \pm 12.74$ years while that of the controls was $23.62 \pm 12.86$ years. The difference in mean age between the two groups was however not statistically significant $(\mathrm{P}=0.968)$. The age range of the respondents was $10-65$ years. Among the myopes, $42(52.5 \%)$ were males and 38 $(47.5 \%)$ females giving a male to female ratio of $1.1: 1$. The control group had $32(40.0 \%)$ males and $48(60 \%)$ females giving a male to female ratio of 2:3.There was a total of 74 males and 86 females giving a ratio of $(\mathrm{M}: \mathrm{F}=1: 1.1)$. This difference in gender representation was however not statistically significant $(\mathrm{p}=0.416)$.

The mean central corneal thickness (CCT) for myopes was $530.34 \pm 49.00 \mu \mathrm{m}$ while that of the control was $533.82 \pm 38.03 \mu \mathrm{m}$. The difference was statistically significant $(\mathrm{P}=0.001)$. In measuring Chisquare for trend, a p-value greater than 0.05 indicates no trend in the increasing levels of Central Corneal Thickness (CCT) as responsible for patients being myopic as compared to non-myopes (controls); as a Mantel-Haenszel test for linear trend showed no statistically significant $\mathrm{p}=0.923\left(\chi^{2}=0.009\right)$. There was no correlation between myopia and CCT $(\mathrm{r}=0.0, \mathrm{r} 2=0.0, \mathrm{CI}=0.45-0.45)$.

\section{Discussion}

There are conflicting reports on the effect of refractive status on CCT. While a study found that myopic subjects had thicker central corneal thickness, ${ }^{12}$ others report thinner $\mathrm{CCT}^{13,14}$ and yet others found no correlation between CCT and myopia. ${ }^{15}$ The statistically significant thinner mean CCT of the myopes compared to the controls and the higher number of myopes with very thin corneas $(<450 \mu \mathrm{m})$ could account for longer axial length following corneo-scleral stretch as it has been reported in previous studies. ${ }^{16,17}$ This progression not only makes the globe longer but also makes the sclera thinner. ${ }^{16,17}$ If the total corneal volume does not increase, we expect that the corneal stroma will become thinner in a similar way to the sclera during myopic progression. This study showed significant thinning of the myopic cornea compared to emmetropes but no correlation was noted between CCT and the myopia. It thus shows that though myopes in our environment have statistically significant thinner cornea, this does not account for their myopic status.

The mean central corneal thickness of myopes in this study was also less than that obtained in a study among Spanish Caucasian myopic 
adults aged $20-40$ years $(550.12 \mu \mathrm{m}),{ }^{18}$ Saudi Arabians $(543.80 \mu \mathrm{m})$ and in an American Caucasian population. ${ }^{19}$ The thinner central corneal thickness observed in this study could be due to involvement of older subjects as it has been reported that corneal thickness decreases with advancing age. ${ }^{20}$ It could also be due to decreased corneal thickness in blacks compared to Caucasians which has been previously reported. ${ }^{21}$

\section{Acknowledgments}

None.

\section{Conflicts of interest}

Authors declare that there is no conflict of interest.

\section{References}

1. Meng W, Butterworth J, Malecaze F, et al. Axial length: an underestimated endophenotype of myopia. Med Hypotheses. 2010;74(2):252-253.

2. Shen M, Fan F, Xue A, et al. Biomechanical properties of the cornea in high myopia. Vision Res. 2008;48(21):2167-2171.

3. Kanski JJ. Clinical Ophthalmology: A Systemic Approach. $6^{\text {th }}$ ed. Edinburgh: Elsevier Butterworth-Heinemann; 2007. 654-656 p.

4. Goldschmidt E. The Mystery of Myopia. Acta Ophthalmol Scand. 2003;81(5):431-436.

5. Leydolt C, Findl O, Drexler W. Effects of change in intraocular pressure on axial eye length and lens position. Eye (Lond). 2008;22(5):657-661.

6. Pruett R. Progressive myopia and intraocular pressure: what is the linkage? A literature review. Acta Ophthalmol Suppl. 1988;185(66):117-127.

7. Castren JA, Pohjola S. Refraction and scleral rigidity. Acta Ophthalmol (Copenh). 1961;39:1011-1014.

8. Fam HB, How AC, Baskara M, et al. Central corneal thickness and its relationship to myopia in Chinese adults. $\mathrm{Br} J$ Ophthalmol. 2006;90(12):1451-1453.

9. Rada JA, Shelton S, Norton TT. The sclera and myopia. Exp Eye Res. 2006;82(2):185-200
10. McBrien NA, Gentle A. Role of the sclera in the development and pathological complications of myopia. Prog Retin Eye Res. 2003;22(3):307-338

11. Chang SW, Tsai IL, Hu FR, et al. The cornea in young myopic adults. Br J Ophthalmol. 2001;85(8):916-920.

12. Kunert KS, Bhartiya P, Tandon R, et al. Central corneal thickness in Indian patients undergoing LASIK for myopia. J Refract Surg. 2003;19(3):378-379.

13. Von Bahr G. Corneal thickness: its measurement and changes. Am J Ophthalmol. 1956;42(2):251-266.

14. Alsbirk PH. Corneal thickness. 1. Age variation, sex difference and oculometric correlations. Acta Ophthalmol Scand. 1978;56(1):95-104.

15. Pfeiffer N, Torri V, Miglior S, et al. Central corneal thickness in the European Glaucoma Prevention Study. Ophthalmology. 2007;114(3):454-459.

16. Lin LL, Shih YF, Tsai CB, et al. Epidemiologic study of ocular refraction among schoolchildren in Taiwan in 1995. Optom Vis Sci. 1999;76(5):275-281.

17. Phillips JR, McBrien NA. Form deprivation myopia: elastic properties of sclera. Ophthalmic Physiol Opt. 1995;15(5):357-362.

18. Garcia-Medina M, Garcia-Medina JJ, Garrido-Fernandez P, et al Central corneal thickness, intraocular pressure, and degree of myopia in an adult myopic population aged 20 to 40 years in southeast Spain: determination and relationships. Clin Ophthalmol. 2011;5:249-258.

19. La Rosa FA, Gross RL, Orengo-Nania S. Central corneal thickness of Caucasians and African Americans in glaucomatous and non glaucomatous populations. Arch Ophthalmol. 2001;119(1):23-27.

20. Whitacre M, Stein R, Hassanein K. The effect of corneal thickness on applanation tonometry. Am J Ophthalmol. 1993;115(5):592-659.

21. Shimmyo M, Ross AJ, Moy A, et al. Intraocular pressure, Goldmann applanation tension, corneal thickness, and corneal curvature in Caucasians, Asians, Hispanics, and African Americans. Am J Ophthalmol. 2003;136(4):603-613. 